\title{
Information Printed on Sugar-Sweetened Beverage Labels: A Comparative Analysis of Australian and Sri Lankan Legal Framework
}

\section{Charith Amidha Hettiarachchi ${ }^{1}$, Sanath Sameera Wijesinghe ${ }^{2}$, Alexandra Jones ${ }^{3}$}

${ }^{1}$ National Institute of Health Sciences, Ministry of Health, Sri Lanka ${ }^{2}$ Dept. of Legal Studies, The Open University of Sri Lanka, Sri Lanka ${ }^{3}$ The George Institute for Global Health, Australia

\section{Abstract}

Sugar is one of the main ingredients in sugar-sweetened beverages (SSBs): a major contributor to added sugar intake in the diet. Excess consumption of added sugars can adversely affect human health mainly by contributing to non-communicable diseases. Information related to sugar content is usually declared on an SSB product in the section titled ingredients, nutrition information panel, non-addition claim and in front-of-pack labelling (FOPL). Various countries have implemented laws to disclose sugar-related information in SSBs. The aim of this research is to assess sugar labelling requirements for SSBs in Sri Lanka against international Codex standards and sugar labelling requirements in Australia. A doctrinal review was conducted based on legal related literatures.

Both Sri Lankan and Australian legislations as well as Codex standards have provisions on ingredients and claims. FOPL is

*Correspondence should be addressed to Dr. Charith Amidha Hettiarachchi, National Institute of Health Sciences, Ministry of Health, Sri Lanka

Email:dr.charith@gmail.com

https://orcid.org/0000-0002-7329-6581

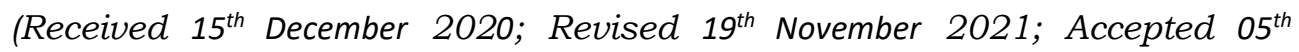
December 2021 (C) OUSL)

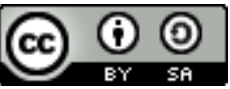

This article is published under the Creative Commons Attribution-Share Alike 4.0 International License (CC-BY-SA). This license permits use, distribution and reproduction in any medium; provided it is licensed under the same terms and the original work is properly cited 
compulsory for Sri Lankan law for selected sugar sweetened beverages. FOPL is neither recommended by Codex currently nor made compulsory by Australian law; however, Australia does have a voluntary code in that regard. NIP, a compulsory requirement in codex standards is mandatory in Australian food label; whereas, it is not mandatory in Sri Lanka. Introducing legal provisions on nutrition information panel would not only align Sri Lankan law with international standards and jurisdictions but also contribute to the control of non-communicable diseases. Highlighting the sugar content raw in the NIP of SSB with 'high sugar' in red colour would further improve the expected outcome. Furthermore, more legal clarity will be achieved in Sri Lanka by adding definitions to terms 'ingredient' and 'non-addition claim'.

Key words: Food Label, Nutrition Information Panel, SugarSweetened Beverages, Nutrition Labelling

\section{Introduction}

\section{Background of the study}

Sugar is one of the main ingredients in sugar-sweetened beverages (SSBs). SSBs are a major contributor to added sugar intake in the diet. Excess consumption of added sugars can adversely affect human health (Keller \& Bucher Della Torre, 2015). Therefore, various countries have implemented laws to disclose sugar-related information in SSBs, allowing consumers to make informed choices about consumption (Grummon et al., 2019).

Sugar-related information on SSB labels can be provided in different forms, for example, sugar-based ingredients may be listed in an ingredient list, sugar may be quantified in a nutritional information panel on back of a pack, and/or sugar may be mentioned in nutrient claims: e.g., 'sugar free'. Sugar may also be incorporated in the scoring of foods for newer forms of simple, graphical, front-of-pack nutrition labelling system. However, there is no uniformity across jurisdictions in terms of regulating these aspects of the label. Many laws are in line with the Codex Alimentarius, a body of international food standards which provides guidance on nutrition labelling broadly, including provisions relevant to sugar labelling.

This research is a comparative study of regulations in Australia and Sri Lanka. Both jurisdictions have their own legislative requirements around sugar information on SSBs. Australia is a federal country constituting of six States and two Territories. However, food labelling is governed by federal legislation in the form of the Australia New Zealand Food Standards Code (FSANZ). Sri Lanka is a unitary 
country and also has a single legal framework regulating food labels throughout the country. Similar to Sri Lanka, Australia is a common law country based on the English law; therefore, comparing the Sri Lankan law with a develop country like Australia which has similar legal principals, would be beneficial for further improvements in the Sri Lankan law.

\section{Scope of the study}

This study summarises the existing state on scientific evidence of the health harms of sugar, particularly as consumed in SSBs. We then present a comparative legal analysis of sugar labelling requirements found in international Codex standards, and national legislation in Australia and Sri Lanka.

\section{Aim of the study}

The aim of this research is to assess sugar labelling requirements for SSBs in Sri Lanka against international Codex standards and sugar labelling requirements in Australia in order to identify gaps in the Sri Lankan law and to make recommendation to Sri Lanka in line with international standards.

\section{Implication of the study}

By comparing the strengths of existing legislation in both countries, this study will make recommendations on how the public health impact of legislation in Sri Lanka may be enhanced.

\section{Theoretical framework}

Sri Lankan and Australian legislations, and international standards regulating sugar information on SSB labels are reviewed, analysed, compared and presented. The study is not based on a particular theory.

\section{Literature Review}

\section{Sugars}

Sugars are a type of carbohydrate, as are starch and fibre. Sugar and starches are digested in the gastrointestinal tract, whilst fibre is not digested. There are two types of sugars, monosaccharides and disaccharides. Glucose and fructose are monosaccharides, whilst sucrose and lactose are disaccharides. Sucrose is present in table sugar, fructose is present in fruits and lactose is present in milk (WHO, 2015a). 
Sugars can occur naturally in foods such as milk (lactose) and fruit (fructose) but can also be added (added sugars) to food and drinks by the manufacturer or consumer. It is these 'added sugars' that dietary guidelines recommend consumers to avoid. At an international level, the World Health Organization (WHO) uses the term 'free sugars' to describe those sugars which should be limited in the diet. These 'free sugars' include all 'added sugars', as well as sugars naturally present in honey, syrups, fruit juices and fruit juice concentrates constitute (WHO, 2015a).

\section{Sugar-Sweetened Beverages}

Beverages are type of food in liquid form, broadly categorised as alcoholic and non-alcoholic beverages. Non-alcoholic beverages include water, dairy based beverages, juice and juice drinks, carbonated drinks, tea and coffee (Hettiarachchi, 2017). SSBs are all non-alcoholic water-based beverages with added sugar but do not include milk-based beverages and 100\% fruit juices (Cancer Council, 2011).

Many factors contribute to the consumption of SSBs, which warrant legislative control by the governments. Most consumers report buying SSBs due to their taste (Australian Bureau of Statistics, 2015). High availability of SSBs in the market positively influences consumption particularly amongst school-aged children (Grimm et al., 2004). Social settings, such as peer groups in educational institutions and workplaces, also influence consumption of SSBs (Hattersley et al., 2009). Marketing and advertising strategies play a major role in increasing consumption - particularly in children, who are often targeted by SSB manufacturers (Brownell \& Warner, 2009; Paes et al., 2015; Reeve \& Gostin, 2019). Research has shown that, SSBs are addictive (Psych Central, 2018). Young people who stopped consuming of SSBs for 3 days reported headaches; reduced inspiration, happiness, and satisfaction, poor focus; and a lack of overall well-being (Felbe et al., 2018). High levels of SSB consumption are a major contributor to added sugar consumption in the diet.

\section{Health Effects of Sugars}

Excess consumption of added sugars has direct and indirect harms on health. Excess consumption of added sugars can contribute to weight gain, obesity, cardiovascular disease, diabetes, and dental caries (WHO, 2003). Obesity is a risk factor for cancer, so high sugar intake can also indirectly result in cancer (World Cancer Research Fund, 2007). Reducing consumption of SSBs would lower the incidence of diabetes, cardiovascular disease and some cancers, improving life expectancy and reducing health care cost (Veerman et al, 2016). 
The WHO recommends free sugar consumption be less than $10 \%$ of total energy intake for both adults and children. Further reduction to below $5 \%$ or roughly $25 \mathrm{~g}$ of free sugar per day would provide additional benefits, particularly for dental health (WHO, 2015b). These health harms create the impetus for policies to address and reduce sugar consumption, through use of effective legislation.

\section{Previous Research on Sugar Information on Sri Lankan SSB labels}

Strengths and deficiencies of Sri Lankan food beverage labels had been assessed by comparing with Codex Alimentarius Standards (Hettiarachchi et al, 2018). Presence on ingredient list, colour code and quantity for sugar level in fruit-based beverages and carbonated drinks were identified as strengths while unavailability of ingredient quantity, title as 'ingredient', nutrient declaration and standard categorization for claim were identified as deficiencies. In another research, attitudes of manufacturers, law enforcing officers and consumers on the Sri Lankan labelling regulations were assessed (Hettiarachchi et al, 2021). Though most consumer were unaware of an existence of a law to regulate food labels, most were in a favourable opinion on the colour code for sugar level and had perceived as very useful.

A cross sectional study had analysed the impact of nutritional labelling on consumer buying behaviour in Kandy, Sri Lanka (Prathiraja \& Ariyawardana, 2011). It was found that $65 \%$ bought products with nutrition labelling due to perceived benefits, suggesting the importance of the nutritional labelling on consumer choice.

\section{Research Methodology}

The study is a doctrinal review. An extensive literature review was performed to identify food labelling laws and regulations relating to sugar, sugar-related information in SSB labels in the selected jurisdictions. International standards, legal standards and regulations were sourced from official websites of international organizations and government bodies of Sri Lanka and Australia. Further, doctoral theses, journal articles, text books and reports were reviewed extensively to enrich the research. 


\section{Findings and Discussion}

All packaged food, including SSBs have labels as per legislative requirements of both Australia and Sri Lanka. Codex standards define 'label' as a 'tag, brand, mark, pictorial or other description, either written, printed, stencilled, marked, embossed or impressed on or attached to a container of food' (Codex Alimentarius, 1991). In Australia, the Food Standard Code defines label as 'any tag, brand, mark or statement in writing or any representation or design or other descriptive matter on or attached to or used or displayed in connection with or accompanying any food or package (Federal Register of Legislation, 2020a). In Sri Lanka, similar to the Codex definition, label is defined as a 'tag, brand, mark, pictorial or other description, either written, printed, stencilled, marked, embossed or impressed on or attached to a container of food' (Government Publication Bureau, 1980). In both jurisdictions, information on sugar content of the product has to be displayed either as a statement or as a pictorial design of any description.

Both jurisdictions and the Codex Standards define sugar as all monosaccharides and disaccharides in food (Federal Register of Legislation, 2020a; Government Publication Bureau, 2016; Codex Alimentarius, 2017). In Sri Lanka, Low sugar is claimed when sugar content is less than $2 \mathrm{~g}$ per $100 \mathrm{ml}$. Medium sugar indicates the sugar content between 2 to $11 \mathrm{~g}$ per $100 \mathrm{ml}$. When the sugar level is more than $11 \mathrm{~g}$ per $100 \mathrm{ml}$, it is considered to be high sugar (Government Publication Bureau, 2005).

Sugar information on a label, can be presented in four formats ingredients, nutrition information panel, claims and front-of-pack nutrition labelling. The next section summarises these requirements in Codex Standards national legislations in Australia and Sri Lanka.

\section{Ingredient list requirements}

The term ingredient is not defined in either jurisdiction. However, according to Codex, an ingredient means any substance, including a food additive, used in the manufacture or preparation of a food and present in the final product, although possibly in a modified form (Codex Alimentarius, 1991).

The ingredient list is mandatory in both jurisdictions. However, in Australia, certain foods are exempted from the requirement of an ingredient list, such as standard alcoholic beverages and food in a small package. Food in a small package means a package (surface area of less than $100 \mathrm{~cm}^{2}$ )(Federal Register of Legislation, 2020a). Further, similar to Codex, the ingredients have to be presented as a 
list in descending order of weight (Federal Register of Legislation, 2020b). In Sri Lanka, ingredients have to be presented as a list in descending order of their proportions (Government Publication Bureau, 2005) and Sri Lankan law does not provide any exemptions. Additionally, Sri Lankan law does not stipulate whether proportion of the ingredient is by weight or volume. Neither Australia nor Sri Lanka displays the weight or proportion of ingredients. Therefore, the consumer must believe the manufacturer's placement of sugar in the descending list of ingredient weight. This is not much as an issue in Australia as the quantity of sugar in the product must also be displayed in the nutrition information panel.

\section{Nutrition Information Panel}

Codex standards recommend a mandatory nutrient declaration and it is defined as a standardized statement or listing of the nutrient content of a food (Codex Alimentarius, 2017).

In Australia, the nutrition information panel (NIP) means nutrition information that is required to be included on a packaged food label in accordance with FSANZ Standards. It is a panel that must appear on the back and quantify specific nutrients per $100 \mathrm{~mL} / \mathrm{g}$ (Federal Register of Legislation, 2020a). The display of the NIP is mandatory in Australia, which has similar regulations as Codex Standards, with specific exclusions for products such as standard alcohol beverages; fruit/vegetables that comprise a single ingredient or category of ingredients; prepared filled rolls; sandwiches; bagels and similar products; and food in small packages (Federal Register of Legislation, 2020c). NIPs on Australian labels provide information on the average quantity of energy in kilojoules or kilocalories. The nutrition information panel must be presented in a standard format showing the average quantity of sugar (alongside protein, fat, saturated fat, carbohydrate and sodium) per serving and per $100 \mathrm{~g}$ or $100 \mathrm{~mL}$ (Federal Register of Legislation, 2020c). The Nutrition Information User Guide provides an example as shown in Figure 1 (FSANZ, 2013). 
Figure 1.

Example Nutrition information panel for Australian food label

\begin{tabular}{|c|c|c|}
\hline \multicolumn{3}{|c|}{ Servings per package: 25} \\
\hline NCIVHIS SIL. IV & $\begin{array}{l}\text { Average Quantity } \\
\text { per Serving }\end{array}$ & $\begin{array}{l}\text { Average Quantity } \\
\text { per } 100 \mathrm{~g}\end{array}$ \\
\hline Energy & $384 \mathrm{~kJ}$ & $2560 \mathrm{~kJ}$ \\
\hline Protein & $4.4 \mathrm{~g}$ & $29.3 \mathrm{~g}$ \\
\hline Fat, total & $7.6 \mathrm{~g}$ & $50.7 \mathrm{~g}$ \\
\hline -saturated & $1.5 \mathrm{~g}$ & $10.0 \mathrm{~g}$ \\
\hline Carbohydrate & $2.0 \mathrm{G}$ & $13.3 \mathrm{~g}$ \\
\hline -sugars & $0.9 \mathrm{~g}$ & $6.0 \mathrm{~g}$ \\
\hline Sodium & $51 \mathrm{mg}$ & $273 \mathrm{mg}$ \\
\hline
\end{tabular}

Note: This example is given in the Nutrition Information User Guide

This legal requirement is similar in other countries, both developed and developing countries including the United Kingdom (Food Standard Agency, 2020), United States (FDA, 2020a) and India (FSSAI, 2020). In addition, from 2020, the United States has taken a further step making it compulsory to display the added sugar amount on labels (FDA, 2020b; Firman, 2019). Currently, Australia too in a process of adding 'added sugar information' into the food label (FSANZ, 2020).

However, in Sri Lanka, the NIP is not mandatory, preventing Sri Lankan consumers from accessing quantified nutritional information on sugar which is important for controlling weight and preventing non-communicable diseases. Whilst, there is no legal requirement in Sri Lanka, most SSBs that are both imported and manufactured by local large-scale companies display a NIP. However, small-scale manufacturers are often unable to bear the additional cost of analysing the nutrient content of their products in the competitive market.

\section{Nutrient content claims}

Codex standards define a claim as 'any representation which states, suggests or implies that a food has a particular quality relating to its origin, nutritional properties, nature, production, processing, composition, or any other quality' (Codex Alimentarius, 1991). The term claim is defined in Australia as 'an express or implied statement, representation, design or information in relation to a food or a property of food which is not mandatory in the Code' (Federal Register of Legislation, 2020a).In Sri Lanka, similar to Codex, a claim means 'any representation which states, suggests or implies that a food has a particular quality relating to its origin, nutritional properties, nature processing, composition, or any other quality'; however, the 
definition has omitted the word 'production' (Government Publication Bureau, 2005).

According to the Australian definition, sugar information in both the ingredient list and nutrition information panel is a mandatory requirement, meaning that sugar information is not a claim. However, the Sri Lankan definition of claim does not as clearly exclude sugar information.

Displaying claims related to nutrition are optional in both jurisdictions. However, if displayed, the claims must adhere to legal requirements. The most relevant types of claims for SSBs are nutrient content claim (e.g. 'sugar free') and non-addition claim (e.g. 'no added sugar'). The nutrient content claim is defined in both Australian and Sri Lankan laws and Codex standards. As per Codex standards, nutrient content claim is a claim describes the level of a nutrient contained in a food (Codex Alimentarius, 1997). In Australia, nutrient content claim is a claim that is about the presence or absence of any specific nutrient stated (Federal Register of Legislation, 2020a). In Sri Lanka, nutrient content claim is a claim which describes the level of a nutrient contained in a type of food (Government Publication Bureau, 2005), which is similar to the Codex standards. Nutrient content claims in both jurisdictions are conditional claims as they must meet certain criteria in order to be permissible. For example, in Sri Lanka, sugar free can be claimed if the sugar content is less than $0.5 \mathrm{~g}$ per $100 \mathrm{~g} / 100 \mathrm{ml}$. Furthermore, false and misleading claims are prohibited in both jurisdictions.

The non-addition claim is not defined in either jurisdiction, although Codex defines as a claim that an ingredient has not been added to a food, either directly or indirectly (Codex Alimentarius, 1997). In Australia 'no added sugar' claim could be declared in foods do not contain added sugars, honey, malt and malt extracts; concentrated fruit juice or deionised fruit juice with certain exceptions (Federal Register of Legislation, 2020d).

\section{Front-of-pack labelling (FOPL)}

Nutrient declarations provide essential information about the nutrient content of foods, but the complexity of the quantitative information in NIP means that it is not readily accessible and is often poorly understood. Front-of-pack labelling (FOPL) provides at-aglance nutritional information for consumers in a simple and graphical form, presented on the front of food packages. FOPL is an intervention to reduce diet-related NCDs and provides convenient, relevant and readily understood information on the front of packs (WHO, 2019). 
Sri Lanka has two additional regulations under Food Act of 1980 relevant to sugar levels in food: Food (Colour Coding for Sugar Level) Regulations 2016 and Food (Colour Coding for Sugar - Salt - Fat) Regulations 2019. However, only the Food (Colour Coding for Sugar Level) Regulation, 2016 is relevant to SSBs as the latter does not include beverages. The 2016 regulation is relevant to carbonated beverages, ready-to-serve beverages, fruit nectars and fruit juices (Table 1).

Table 1.

Sri Lankan legal definitions of beverage types

\begin{tabular}{ll}
\hline \multicolumn{1}{c}{$\begin{array}{c}\text { Beverage } \\
\text { type }\end{array}$} & \multicolumn{1}{c}{ Legal definition } \\
\hline $\begin{array}{l}\text { Carbonate } \\
\text { beverage }\end{array}$ & $\begin{array}{l}\text { Non-alcoholic, water-based beverage containing } \\
\text { dissolved carbon dioxide, sugar other permitted } \\
\text { ingredients }\end{array}$ \\
Ready to & $\begin{array}{l}\text { Fruit drink intended for consumption without } \\
\text { dilution and prepared from unfermented but } \\
\text { serve } \\
\text { fermentable fruit juice or puree or concentrate with } \\
\text { or without some of the pulp and containing any } \\
\text { soluble sweetener and portable water }\end{array}$ \\
Fruit nectar & $\begin{array}{l}\text { Unfermented but fermentable product obtained by } \\
\text { adding water with or without the addition of sugars, } \\
\text { honey, treacle, and/or syrups and/or sweeteners } \\
\text { and other permitted ingredients to fruit juice }\end{array}$ \\
Fruit juice & $\begin{array}{l}\text { Unfermented but fermentable liquid obtained from } \\
\text { the edible part of appropriately mature and fresh } \\
\text { fruit maintained in sound condition by suitable } \\
\text { means }\end{array}$ \\
\hline
\end{tabular}

Note: Definitions are stipulated in the Food (Colour coding for Sugar Level) regulations, 2016

As per the legal definitions of all ready-to-serve beverages, fruit nectars and fruit juices are fruit-based beverages. Therefore, Sri Lankan law excludes non-fruit based and non-carbonated beverages with added sugar. As per the regulations, the corresponding colour category, according to the sugar content in grams per $100 \mathrm{ml}$, and a statement in three languages (Sinhala, Tamil and English) must be displayed: Green for low sugar $(<2 \mathrm{~g} / 100 \mathrm{ml})$, Amber for medium sugar $(2-11 \mathrm{~g} / 100 \mathrm{ml})$ and red for high sugar $(>11 \mathrm{~g} / 100 \mathrm{ml})$ (Government Publication Bureau, 2016). The provisions are summarized in Table 2 (Hettiarachchi, 2017). 
Table 2.

Sri Lankan colour code provisions for sugar level

\begin{tabular}{|c|c|}
\hline Sugar level & Colour code \\
\hline $\begin{array}{l}\text { Numerical description of the } \\
\text { sugar content } \\
>\quad<2 \mathrm{~g} / 100 \mathrm{ml} \\
>\quad 2-11 \mathrm{~g} / 100 \mathrm{ml} \\
>\quad>11 \mathrm{~g} / 100 \mathrm{ml}\end{array}$ & $\begin{array}{l}\text { Colour of the circle } \\
\text { should be according to } \\
\text { the sugar level as follows. } \\
\text { Diameter of the colour } \\
\text { circle should be not less } \\
\text { than } 1 \mathrm{~cm}\end{array}$ \\
\hline $\begin{array}{l}\text { Description of the sugar level } \\
>\text { High sugar (for }>11 \mathrm{~g}) \\
>\text { Medium sugar (for }>2-11 \mathrm{~g} \text { ) } \\
>\text { Low sugar (for }<2 \mathrm{~g})\end{array}$ & $<2 g-$ Green \\
\hline $\begin{array}{l}\text { Should be in all } 3 \text { languages } \\
\text { (English, Sinhala and Tamil) }\end{array}$ & $\begin{array}{l}2-11 g- \\
\text { Amber } \\
\text { (yellow to } \\
\text { orange) }\end{array}$ \\
\hline Font size not less than $1.5 \mathrm{~mm}$ & $>11 g-\operatorname{Red}$ \\
\hline
\end{tabular}

Note: Source is the Food (Colour Coding for Sugar Levels) Regulations, 2016

Australia does not have a legislated FOPNL system, however since 2014, it has implemented the Health Star Rating system on a voluntary basis. The Health Star Rating rates foods overall from 0.5 to 5.0 stars using an algorithm that considers total sugar content as one of seven food components included (Health Star Rating, 2020).

At an international level, Codex is currently working on international guidance on front-of-pack labelling, but it is anticipated that the result of this process will not be to prescribe a single FOPNL but rather to set out principles for countries considering these policies (Thow et al., 2020).

The sugar content is determined by analysing a beverage sample in a laboratory. However, manufacturers use equipment called the Brix meter for measuring sugar concentration, which measures the percentage of sugar content as Brix degrees. One Brix Degree is equal to $1 \mathrm{~g}$ of sugar (Sucrose) in $100 \mathrm{~g}$ of solution and not in $100 \mathrm{ml}$. Therefore, in practice the sugar content declaration is not legal, as it is measured in $100 \mathrm{~g}$, while the regulations require it to be measured 
in $100 \mathrm{ml}$. This means the colour code regulations are not correctly implemented, in-addition to their failure to include non-fruit based and non- carbonated beverages with added sugar. Furthermore, the labelling laws are poorly implemented in Sri Lanka by manufacturers and enforcement officers (Hettiarachchi, 2017). Hence, it is reasonable to argue that these weaknesses in implementation are limiting the potential public health impact of FOPNL in informing Sri Lankan consumers of the true sugar content of these products, and supporting them to make healthier choices.

The NIP provides more information on sugar than the colour code. Even though sugar is included under the carbohydrates amount on the NIP, it is also displayed separately. The NIP provides the sugar amount per serving or per $100 \mathrm{ml} / 100 \mathrm{~g}$, whereas the colour code only provides a range. As the exact sugar amount is required to calculate the energy value of the sugar, the energy value per serving or per $100 \mathrm{ml}$ can only be calculated from the NIP. The total volume of the product is available in the label as the net content or net volume, so by combining the net volume and sugar content per $100 \mathrm{ml}$ or per serving, the total sugar amount can be calculated if necessary. Serving size is usually decided by the manufacturer, so $100 \mathrm{ml} / 100$ $\mathrm{g}$ could be used for a precise calculation and to allow standardised comparison between similar products. Furthermore, the NIP also includes information on other nutrients if relevant and energy levels.

Iran has more recently introduced an alternative label that presents a hybrid form of the NIP and a colour-coded FOPL. The NIP is overlaid with colour coding over the quantified nutrient information provided for fat, sugar, salt, trans fatty acids and energy content. Green indicates low or a little amount of the corresponding nutritional risk factor, yellow indicates a moderate amount and red shows a high amount, with thresholds set for each colour (WCRF, 2018). It is implemented to reduce non communicable disease burden in Iran. Poor media involvement and poor public awareness are some of challenging factors in Iran to achieve a successful outcome (Edalati et al., 2019).

\section{Conclusions}

Adverse health effects of the excess consumption of sugars were recognised. Both Sri Lankan and Australian legislations as well as Codex standards have provisions on sugar-related information on the labels of SSB. Several notable omissions and deviations from international standards were noted in the Sri Lankan law especially on nutritional information which need to be corrected in future legal amendments. 
Even though, definitions are important for technical as well as legislative matters, Sri Lanka does not define the terms 'ingredient', 'non-addition claim': defining them as per Codex standards would make legal provisions clearer. Furthermore, stipulating the measurement (weight or volume) of proportion of ingredients and displaying the proportion with each ingredient would make this information more credible to the consumer.

The quantity of sugar in a product is displayed in the NIP, which is mandatory on beverage labels in most countries. It assists consumers deciding on portion size and energy intake as well as helps to plan their immediate as well as their overall diet. In Australia, as recommended by codex standards, these NIPs are mandatory. However, in Sri Lanka it is still not mandatory to display the NIP. Instead, alternative FOPL requirements in Sri Lanka provided simplified information on amount of sugar in the product within specified ranges only, using traffic light colour coding. Sri Lanka does not have a reasonable excuse for not making NIP compulsory, except the extra financial burden for small scale manufacturers which can be overcome by exempting them or allowing additional time for implementation.

Sugar content in the colour code is legally expected to be measured for $100 \mathrm{ml}$ and it is not compatible with the Brix degree which measures sugar content for $100 \mathrm{~g}$. Allowing to measure sugar content by weight (grams) as an alternative, would make this legal provision more practical.

Introducing of NIPs for Sri Lankan food labels, in addition to existing FOPL requirements, could be beneficial in supporting consumers to reduce excess sugar consumption; therefore, there is a need to for NIPs to be incorporated in to the Sri Lankan food label. Considering the financial cost of analysing nutrient content accurately, it is reasonable to exempt the small-scale manufacturers and those producing small packages- less than $100 \mathrm{ml}$ - from the mandatory display of NIPs, or allowing them to quantify sugar using reasonable alternative methods eg. using estimations from national nutrition databases of similar products. Highlighting the sugar content raw in the NIP of SSB with 'high sugar' in red colour would improve the effective usage of NIP by consumers.

\section{Abbreviations}

FOPL - Front-of-Pack Labelling

FSANZ - Food Standards Australia and New Zeeland

NIP - Nutrition Information Panel 


\section{Acknowledgements}

Authors sincerely appreciate the academic and non-academic staff of Department of Public Health, Faculty of Health, University of Technology Sydney, Australia for their valuable assistance.

Authors pay gratitude to the Post Graduate Institute of Medicine, University of Colombo and Ministry of Health Sri Lanka for their support and guidance

\section{References}

Australian Bureau of Statistics. (2015). Australian Health Survey: Nutrition First Results - Foods and Nutrients, 2011-12. Consumption of Sweetened Beverages. Canberra. Australia. https://www.abs.gov.au/ausstats/abs@.nsf/lookup/

Brownell, K. D. \& Warner, K. E. (2009). The Perils of Ignoring History: Big Tobacco Played Dirty and Millions Died. How Similar Is Big Food? The Milbank Quarterly, 87(1), 259-294.

https://doi.org/10.1111/j.1468-0009.2009.00555.x

Cancer Council. (2011). Sugar -sweetened beverages -position statement. Cancer Council. Australia.

https://wiki.cancer.org.au/policy/Position_statement

Codex Alimentarius. (2017). Codex guidelines of nutrition labelling CAC/GL 2-1985. Codex Alimentarius Commission.

Codex Alimentarius. (1991). Codex general standard for the labelling of prepackaged foods - CODEX STAN 1-1985 (Rev. 1-1991). Codex Alimentarius Commission.

Codex Alimentarius. (1997). Nutrition and Health Claims (CAC/GL 23-1997). Codex Alimentarius Commission.

Edalati, S., Omidvar, N., Roudsari, A. H., Ghodsi, D. \& Zargaraan, A. (2019). Development and implementation of nutrition labelling in Iran: A retrospective policy analysis. International Journal of Health Planning and Management, 35(4).

https://www.researchgate.net/publication/337163487.

DOI $10.1002 / \mathrm{hpm} .2924$

Federal Register of Legislation. (2020a). Australia New Zealand food standard 1.1.2 - definitions used throughout the code, 2019. Federal Register of Legislation. Australia.

https://www.legislation.gov.au/Details/F2018C00944 
Federal Register of Legislation. (2020b). Australia New Zealand food standard 1.1.4 - Information requirements - statement of ingredients, 2015. Federal Register of Legislation. Australia, https://www.legislation.gov.au/Details/F2018C00944

Federal Register of Legislation. (2020c). Australia New Zealand food standard 1.1.8 - Nutrition information requirements, 2018. Federal Register of Legislation. Australia. https://www.legislation.gov.au/Details/F2018C00944

Federal Register of Legislation. (2020d). Australia New Zealand food standard - Schedule 4 - Nutrition, health and related claims, 2017. Federal Register of Legislation. Australia.

https://www.legislation.gov.au/Details/ F2017C00711

Felbe, J., Thompson, H. R., Patel, A. \& Madsen, K. A. (2018). Potential addictive properties of sugar-sweetened beverages among adolescents. Science direct.

https://www.ncbi.nlm.nih.gov/pmc/articles/PMC6488513/

Firman, T. (2019). This is how much sugar you can eat per day. Good Housekeeping.

https://www.goodhousekeeping.com/health/diet-nutrition/

Food and Drug Administration. (2020a). Daily value on the new nutrition and supplement facts labels. Food and Drug Administration. United States.

https://www.fda.gov/food/new-nutrition-facts-label/

Food and Drug Administration. (2020b). Food Labelling \& Nutrition. Food and Drug Administration. United States.

https://www.fda.gov/food/new-nutrition-facts-label/

Food Safety and Standards Authority of India. (2020). FSSAI guideline on labelling of food products. Packaging-Labelling. https://www.packaging-labelling.com/articles/

Food Standard Agency. (2020). Nutrition-labelling. United Kingdom. https://www.food.gov.uk/business-guidance/

Food Standard Australia and New Zealand. 2013, Nutrition information user guide.

https://www.foodstandards.gov.au/code/userguide/Documents /Userguide

Food Standard Australia and New Zealand. 2020, Sugar labelling. https://www.foodstandards.gov.au/consumer/labelling 
Government Publication Bureau. (1980). Food Act of 1980. Government Publication Bureau. Sri Lanka.

Government Publication Bureau. (2005). Food (Labelling and Advertising) Regulations 2005. Government Publication Bureau. Sri Lanka.

Government Publication Bureau. (2016). Food (Colour Coding for Sugar Level) Regulations 2016. Government Publication Bureau. Sri Lanka.

Grimm, G. C., Harnack, L. \& Story, M. (2004). Factors associated with soft drink consumption in school-aged children. J. Am. Diet Assoc. 2004 Aug, 104(8), 1244-9.

http://www.ncbi.nlm.nih.gov/pubmed/ 15281041

Grummon, A. H., Hall, M. G., Taillie, L. S. \& Brewer, N. T. (2019). How should sugar-sweetened beverage health warnings be designed? A randomized experiment. Preventive Medicine 2019, $121,158-166$.

https://doi.org/10.1016/j.ypmed

Hattersley, L., Irwin, M., King, L. \& Allman-Farinelli, M. (2009). Determinants and patterns of soft drink consumption in young adults: a qualitative analysis. Public Health Nutrition 2009 Oct, 12(10), 1816-22.

http://www.ncbi.nlm.nih.gov/pubmed/19195421

Health Star Rating. (2020). Health Star Rating System.

http://www.healthstarrating.gov.au/internet/healthstarrating

Hettiarachchi, C. A. (2017). Compliance of labels of beverages to the food labelling regulation and effectiveness of an advocacy package in improving adherence to labelling regulations by food industry. MD theses, Post Graduate Institute of Medicine, University of Colombo. Sri Lanka.

Hettiarachchi, C. A., Arnold, S. M. \& Nandasena, S. (2017). Strengths and deficiencies of beverage labelling regulations of Sri Lanka, Journal of college of Community Physiciansof Sri Lanka, 24(2), 110. https://jccpsl.sljol.info/724/volume/24/issue/2/

Hettiarachchi, C. A., Arnold, S. M. \& Nandasena, S. (2021). Attitudes of manufacturers, law enforcing officers and consumers on the Sri Lankan labelling regulations: a qualitative study. Journal of college of Community Physicians of Sri Lanka, 27(1), 289-301. https://jccpsl.sljol.info/750/volume/27/issue/1/ 
Keller, A. \& Bucher Della Torre, S. (2015). Sugar-Sweetened Beverages and Obesity among Children and Adolescents: A Review of Systematic Literature Reviews. Childhood Obesity, 11(4), 338346.

https://doi.org/10.1089/chi.2014.0117

Mayo Clinic. (2020). Metabolism and weight loss. How you burn calories.Mayo Clinic.

https://www.mayoclinic.org/healthy-lifestyle/weight-loss/indepth/

Paes, M. V., Hesketh, K., O'Malley, C., Moore, H., Summerbell, C. \& Griffin, S. (2015). Determinants of sugar-sweetened beverage consumption in young children: a systematic review. Obes Rev 2015 Nov, 16(11). 903-913.

http:/ /www.ncbi.nlm.nih.gov/pmc/articles/PMC4737242/

Patel, K. (2013). How are carbohydrates converted in to fat deposits? Examin.com.

https://examine.com/nutrition/how-are-carbohydratesconverted-into-fat-deposits.

Prathiraja, P. H. K. \& Ariyawardana, A. (2011). Impact of Nutritional Labelling on Consumer Buying Behaviour. Sri Lankan Journal of Agricultural Economics, 5,35-46.

https://doi.org/10.4038/sjae.v5i0.3475

PsychCentral. (2018). Are sugar-sweetened beverages addictive? https://psychcentral.com/news /2018/11/21/

Reeve, B. \& Gostin, L. O. (2019). "Big" Food, Tobacco, and Alcohol: Reducing Industry Influence on Noncommunicable Disease Prevention Laws and Policies Comment on "Addressing NCDs: Challenges from Industry Market Promotion and Interferences." International Journal of Health Policy and Management, 8(7), 450454. https: //doi.org/10.15171/ijhpm.2019.30

Stass, J. (2016). What happen to your body after an hour eating sugar? Independent.

https:/ / www.independent.co.uk/life-style/food-anddrink/features/what-happens-to-your-body-an-hour-aftereating-sugar-a6879026

Thow, A. M., Jones, A., Schneider, C. H. \& Labonte, R. (2020). Increasing the public health voice in global decision-making on 
nutrition labelling. Globalization and Health 16.1 (2020), 1-6. https://globalizationandhealth.biomedcentral.com

Veerman, J. L., Sacks, G., Antonopoulos, N. \& Martin, J. (2016). The Impact of a Tax on Sugar-Sweetened Beverages on Health and Health Care Costs: A Modelling Study. PLoS One 2016 Apr 13, 11(4), e0151460.

http://www.ncbi.nlm.nih.gov/pubmed/27073855

World Cancer Research Fund, American Institute for Cancer Research. (2007). Food, nutrition, physical activity, and the prevention of cancer: a global perspective. Washington DC: AICR. https://www.wcrf.org/dietandcancer

World Cancer Research Fund International. (2018). Nourishing framework. World Cancer Research Fund International. https://www.wcrf.org/sites/default/files/Nutrition-labels.

World Health Organization. (2003). Diet, nutrition and the prevention of chronic diseases. WHO technical report series. WHO Geneva. Switzerland.

http://apps.who.int/iris/bitstream/10665/42665/1/

World Health Organization. (2015a). WHO calls on countries to reduce sugars intake among adults and children. World Health Organization. Geneva.

https://www.who.int/mediacentre/news/releases/2015/sugarguideline/en/

World Health Organization. (2015b). Guideline-Sugars intake for adults and children. WHO. Geneva.

http://who.int/nutrition/publications/guidelines/sugars_intake /en/

World Health Organization. (2019). Guiding principles and framework manual for front-of-pack labelling for promoting healthly diets. WHO. Geneva.

http://who.int/nutrition/publications 